\title{
The ecology of subindividual variability in plants: patterns, processes, and prospects
}

\author{
Carlos M. Herrera \\ Department of Evolutionary Ecology, Estación Biológica de Doñana, CSIC, Avda. Americo Vespucio 26, \\ Isla de La Cartuja, 41092 Seville, Spain \\ Correspondence to: Carlos M. Herrera (herrera@ebd.csic.es)
}

Received: 8 November 2017 - Accepted: 5 December 2017 - Published: 8 December 2017

\begin{abstract}
Diversification of ecology into subdisciplines that run from macroecology to landscape, community, and population ecology largely reflects its specialization on different segments of the spatial gradient over which recognizable ecological patterns and processes occur. In all these cases, the elemental units involved in the patterns and processes of interest to ecologists are individuals from the same or different species. No distinct flavor of ecology has yet emerged that focuses on patterns and processes revolving around the lowermost end of the spatial gradient, which in the case of plants corresponds to the within-individual domain. Intraindividual heterogeneity in organ traits, however, is quantitatively important and has multiple consequences for plant individuals, populations, and communities, and for animal consumers as well. This paper first provides an overview of current knowledge on plant traits that vary subindividually, the magnitude of subindividual variation, and its spatial patterning. Examples will then be presented on the consequences of subindividual variation for plants and animal consumers at individual, population, or community levels. Finally, the recently emerging links between genetics, epigenetics, subindividual variation, and population ecology will be illustrated using results on variation in seed size, a functional plant trait playing an important role in plant population dynamics. Further observational and experimental studies are needed which link ecological and phenotypic measurements of plants to their epigenetic and genetic characteristics, in order to understand the three-way relationships between subindividual variability, genetic features, and epigenetic mosaicism. Another proposed line of inquiry should focus on evaluating whether subindividual epigenetic mosaics eventually translate into epigenetically heterogeneous progeny, thus contributing to the maintenance of population and community functional diversity.
\end{abstract}

\section{Introduction}

Following its formal definition by Ernst Haeckel as the science that studies the relationships between organisms and the environment, ecology steadily experienced a process of diversification that eventually led to the appearance of a series of distinct subdisciplines. To a considerable extent, the historical diversification of ecology into subdisciplines reflects a progressive specialization on different segments of the broad gradient of spatial scales on which pertinent ecological patterns and processes can be identified and studied. At the high end of the spatial-scale gradient, the mission of macroecology is to describe and understand the causes and consequences of ecological processes on very large spatial scales (say, $10^{6}-10^{7} \mathrm{~m}$ ) such as, e.g., biome differences in productivity or planetary-scale patterns in biodiversity. At progressively smaller spatial scales, landscape ecology focuses, among other things, on the ecology of metapopulations and metacommunities at the regional level $\left(10^{4}-10^{5} \mathrm{~m}\right)$, while community ecology and population ecology are mostly concerned with the functioning at local scales $\left(10^{1}-10^{3} \mathrm{~m}\right)$ of multi-species assemblages or single-species populations, respectively. Common to all these subdisciplines is the fact that, irrespective of spatial scale, the elemental units that build up the patterns and participate in the processes of interest to ecologists are individuals from the same (population ecology) or different species (rest of the subdisciplines). No coherent subdiscipline or distinct flavor of ecology has so far emerged whose focus is placed on the ecological sig- 
nificance of patterns and processes that take place around the lowermost end $\left(10^{0}-10^{1} \mathrm{~m}\right)$ of the macroscopic spatial gradient envisaged above. This segment of the spatial scale would roughly correspond to within-individual variation, and its predominant neglect is well exemplified by the unambiguous subtitle, "From individuals to ecosystems", on the cover of one of the most authoritative ecology textbooks (Begon et al., 2006). In recent years, however, increasing evidence has shown that such very small-scale, intraindividual variation may have manifold ecological consequences for the population and community ecology of both animals and plants (Herrera et al., 2015; Alonso et al., 2017; Arceo-Gómez et al., 2017, and references therein).

In most animals, subindividual variation of ecological relevance is mostly sequential in nature, as it generally arises from ontogenetic and/or seasonal changes in the organismal features of individuals. Sequentiality of subindividual variation means that, at different moments or ontogenetic stages in an animal's adult life, a given individual will exhibit variable states of functional or structural features (e.g., behavior, coloration, digestive organ size; Piersma and Lindström, 1997; Delhey and Kempenaers, 2006; Stamps et al., 2012). Plants differ from animals with respect to within-individual variation in a most profound way. As noted long ago by Lloyd (1984, p. 379), "a plant produces a considerable number of structures of one kind [and] this simple feature can explain a major difference in the variation patterns exhibited by plants and animals." Although plants and animals share the sequential (seasonal or ontogenetic) component of subindividual variation (e.g., contrasting leaf size and shape between juveniles and adults in some heterophyllous plants), vascular plants stand uniquely apart because of the existence of a strong simultaneous component of subindividual variation that arises naturally from their modular construction.

The modular construction of plant bodies by continual organogenesis and reiterated production of homologous, functionally equivalent structures is a truly quintessential, ancestral feature of the body plan of vascular plants (Herrera, 2009). The ecological consequences of plant modularity have been addressed from three main angles. First, following White's (1979) pioneering treatment of plant individuals as metapopulations of repeated modules, demographically inspired investigations have dealt with the consequences of differential growth and survival of modular subunits, particularly in long-lived species characterized by extensive clonal proliferation. Second, there are physiologically inspired studies that have examined the effects of modularity on small-scale spatial patterns of within-plant distribution of water, photosynthates and other products (Marshall, 1996; Price et al., 1996), and the resulting compartmentalization of plant bodies into a series of relatively independent "integrated physiological units" (Watson, 1986; Orians and Jones, 2001). The third perspective on plant modularity, and the one this paper will be exclusively concerned with, emphasizes the appearance of a distinctive source of phenotypic variance, namely the within-plant or subindividual component. An inevitable consequence of a multiplicity of modules being simultaneously borne by individual plants is a certain variability in the characteristics of the copies of the same organ (leaves, flowers, fruits, seeds) produced in different modules of the same individual. As first suggested by Suomela and Ayres (1994) and documented at length by Herrera (2009), within-individual variability in organ traits is an emergent property of plant individuals brought about by their modular construction through reiteration of elemental subunits (metamers) and the associated repetition of homologous structures that perform the same function (leaves, flowers, fruits, seeds).

In this paper, I will first provide a concise review of current knowledge on the nature of plant traits that vary subindividually, the magnitude of subindividual variation relative to variation between individuals, and its spatial patterning. Next I will highlight some of the ecological consequences of subindividual variation for plants and their animal consumers at the individual, population, and community levels. All the preceding aspects were thoroughly reviewed by Herrera (2009); thus, whenever possible I will consider here preferentially those findings obtained by more recent investigations that complement, expand, or corroborate the conclusions of that earlier review. Finally, I will consider the little explored connections between subindividual variation, population ecology, genetics, and epigenetics, which will be illustrated by results of recent investigations on the epigenetic correlates of seed mass variation.

\section{Traits and magnitude of subindividual variation}

Studies on subindividual variation in plants have traditionally tended to focus on the relatively infrequent instances of discontinuous variation involving morphologically or functionally distinct variants of reiterated homologous structures, typically leaves (heterophylly), fruits (heterocarpy), and seeds (heteromorphism) (see Wells and Pigliucci, 2000, Imbert, 2002, and Matilla et al., 2005, for reviews). Examples include the coexistence of prickly and nonprickly leaves in the same crown of individual trees (Herrera and Bazaga, 2013) or the simultaneous production by individual plants of distinct seed morphs with contrasting dispersal ability (Imbert, 2002). Ecologists interested in the evolution of plant gender and mating systems have long scrutinized the causes and consequences of the production of distinct floral sex morphs by the same individual (Barrett, 1998). In contrast, continuous within-plant variation in quantitative traits of homologous organs remains comparatively unexplored from an ecological perspective despite being a quintessential plant feature (Herrera, 2009). I will focus on this ubiquitous form of subindividual variation for the rest of this paper.

Continuous subindividual variation is the rule for virtually every conceivable continuous trait of any reiterated homol- 
ogous structure (Herrera, 2009). Importantly, many of the traits that vary within individual plants are known for their functional nature; i.e., they have potential effects on the fitness of individuals or the environment (Pérez-Harguindeguy et al., 2013). These include simple traits like leaf length, fruit size, or seed mass, but also less apparent features such as concentration of nutrients and secondary compounds in leaves, length of seed dormancy, or sugar concentration in floral nectar or the pulp of berries. Recent studies have continued furnishing examples of relatively cryptic continuous traits that, when properly sampled, exhibit substantial subindividual variation. These include, among other things, leaf stomatal traits (Herrera et al., 2015), leaf nutrients (Wetzel et al., 2016), sugar composition of floral nectar (Herrera et al., 2006; Canto et al., 2007; Zywiec et al., 2012), distance between anthers and stigma (Dai et al., 2016; Arceo-Gómez et al., 2017), tannin content of seeds (Shimada et al., 2015), fruit shape (Larrinaga and Guitián, 2016), and global DNA cytosine methylation of the genome (Alonso et al., 2017).

Subindividual variability in functional traits, however, is not ecologically interesting in itself, since even tightly controlled industrial processes fail to produce perfect copies of simple items due to minor stochastic fluctuations in the production equipment. It is intuitive to postulate that the greater the subindividual variability in a given trait, the more likely it will be that a such variation may have some ecological relevance. One method for assessing the extent of subindividual variation is to gauge it by comparison with the extent of variation between individual means for the same trait. This can be achieved, for instance, by estimating the proportion of population-wide variance contributed by subindividual variation, or in other words, by partitioning the population-wide variance of the trait of interest into its within- and among-individual components (Herrera et al., 2015). Estimates of the within-individual variance component $\left(\mathrm{VAR}_{\text {within }}\right.$ hereafter) for a variety of flower, fruit, leaf, and seed traits are shown in Fig. 1a. There was considerable spread of $\mathrm{VAR}_{\text {within }}$ within each organ type, which reflects variation across species and also between different traits for the same organ (Herrera et al., 2015). Despite the broad spread, however, there was a clear trend for $\mathrm{VAR}_{\text {within }}$ to exceed the variance between individual means for all organs except flowers. This implies that most population-wide variance in functional organ traits occurs within the restricted spatial domain of individual plants; that organ trait value distributions for different individuals tend to overlap extensively (Fig. 1b); and that neglecting subindividual variation to focus exclusively on individual means is bound to miss a large fraction of the range of functional variation represented in plant populations. Insofar as the organ traits concerned possess some ecological relevance, e.g., by influencing some important ecological process or playing a role in the appearance of ecological patterns, the preceding implications call for a consideration of the ecological significance of subindividual variation. In the following sections I will present a (a)

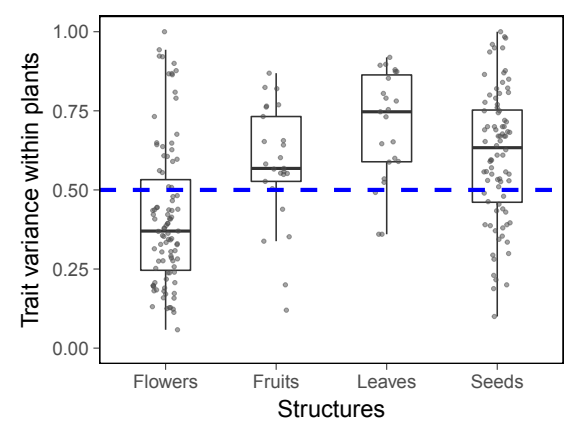

(b)

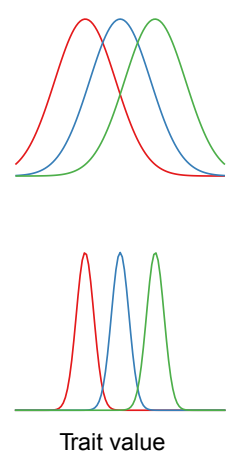

Figure 1. (a) Within-plant variability for a variety of continuously varying flower, fruit, leaf, and seed traits, as estimated by the proportion of population-wide variance in the trait that is accounted for by differences between organs produced by the same plant. The horizontal dashed line denotes the level above which subindividual variance is greater than variance between individual means. Each dot corresponds to an independent estimate $(N=95,25,23$, and 84 estimates for flower, fruit, leaf, and seed traits, respectively). Redrawn from Fig. 3.2 in Herrera (2009). (b) Schematic comparison of hypothetical extremes of high (top) vs. low (bottom) levels of subindividual variation in a continuously varying organ trait for a given set of invariant individual means. Curves represent withinplant frequency distributions of trait values for three different individuals (color coded). Individual means are the same in the upper and lower graphs.

non-exhaustive review of ecological patterns and processes, either established or putative, that are potentially under the influence of subindividual variation in functional traits of reiterated organs.

\section{Spatial patterns: microgradients and environmental grain}

Subindividual variation in organ trait values is often related to some spatial reference system, such as height above ground or compass direction, and in these cases such relationships will give rise to distinct microspatial gradients. Long known examples include predictable relationships between height above ground and the size, photosynthetic capacity, specific area, and nitrogen and phosphorus content of leaves in individual trees (Ellsworth and Reich, 1993; Casella and Ceulemans, 2002; Osada et al., 2014). For example, leaves from upper positions in the crown consistently have a lower water content than those from lower positions in the deciduous tree Prunus mahaleb (Fig. 2). In other cases, within-crown gradients in leaf composition and water content are related to compass orientation (Le Roux et al., 1999; Perica, 2001; Herrera, 2009). In Olea europaea trees, functional leaf traits related to light interception and photosynthetic performance vary according to orientation and position within the crown (Escribano-Rocafort et al., 2016, 2017). Spatial 


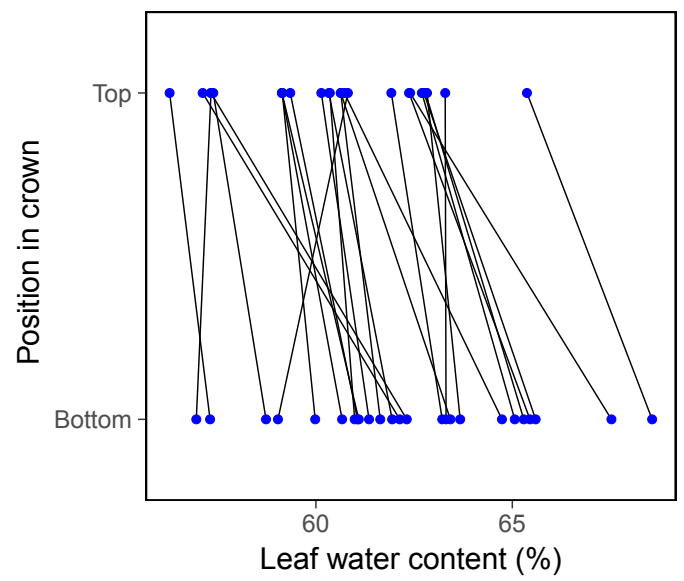

Figure 2. Vertical gradients in leaf water content within the crowns of Prunus mahaleb trees. Each line connects mean values for water content in leaves from the top and bottom positions of an individual $(N=25$ trees). Based on data from Alonso (1997, and unpublished).

microgradients will also arise when organ trait values vary regularly along nodal positions of linear supporting structures such as branches or inflorescences. Traits that vary predictably along these linear plant axes include anatomical features and chemical composition of leaves, nutritional characteristics of seeds, and structural and functional floral traits (Bennett et al., 2003; Guitián et al., 2004; Young et al., 2010; Austen et al., 2015; Herrera et al., 2015). For example, in the perennial herb Helleborus foetidus, leaf stomatal density increases, and mean stomatal size decreases, from basal to distal nodal positions along vegetative ramets (Herrera et al., 2015).

Irrespective of the specific details on how it is spatially organized within individual plants or plant parts, subindividual variation in functional traits of organs will have the crucial ecological consequence of altering environmental grain size for ecologically relevant parameters. It will promote "finegrainedness", or small-scale "granularity", of the environment relative to a hypothetical situation where within-plant homogeneity prevailed, as proposed schematically in Fig. 3. Very low and very high $\mathrm{VAR}_{\text {within }}$ values for a trait will correspond by definition to situations where organs resemble strongly and weakly, respectively, other organs in the same plant with regard to that trait (i.e., high and low intraclass correlations, respectively). Strong trait correlations between organs in the same plant will produce coarser grained environments than weak correlations, and the corresponding variograms will also differ widely (Fig. 3).

\section{Individual-centered patterns: variability as an individual property}

From an ecological perspective, an important aspect of subindividual variation in functional organ traits is that conspecific individuals in a population differ in the degree of internal heterogeneity. In other words, subindividual variability should be considered in itself as an individual property, because "individual plants not only have their characteristic means, but their characteristic standard deviations" as well (Haldane, 1957, p. 312; see also Haldane, 1959, Roy, 1959, Paxman, 1956, and Suomela and Ayres, 1994, for further antecedents to this view). This general principle was named the "Haldane-Roy conjecture" by Herrera (2009), where data for a broad variety of functional organ traits from many species were gathered which unequivocally supported the generality of the phenomenon in plant populations. In addition, a within-plant variability continuum was shown to occur in most species, with populations generally comprising phenotypically constant to highly variable individuals, which ultimately means that the component of populationwide variance in an organ trait caused by within-plant variation is not distributed equally among individuals. Recent studies have corroborated and expanded these conclusions by showing that conspecific individuals differ in variability of leaf functional traits (Herrera et al., 2015), seed mass (Herrera et al., 2014; Shimada et al., 2015), fruit size (Sobral et al., 2013), seed tannin content (Shimada et al., 2015), and stigma-anther separation of flowers (Dai et al., 2016; ArceoGómez et al., 2017). In a large sample of plants of the perennial herb Helleborus foetidus, the within-plant coefficient of variation (within-plant standard deviation/individual mean) for stomatal index, stomatal density, stomatal length, and specific leaf area all ranged widely between plants (Fig. 4), thus denoting considerable individual variation in the magnitude of subindividual functional heterogeneity.

\section{Ecological effects of subindividual variation}

Internal heterogeneity of individual plants in functional features of reiterated organs is apt to have a variety of ecological consequences. The importance of the effects will simultaneously depend on the magnitude of the variability, the latter's ultimate impact on spatial "graininess" of trait values, and the nature of the ecological process(es) in which the organs and the traits are involved. As the examples provided in the following sections will show, ecological effects of subindividual variation can take place not only at the individual level, but also at the plant population and plant community levels. In other words, subindividual plant variation possesses some explanatory value for the interpretation of ecological patterns that occur in populations and communities. A thorough review of the ecological consequences of subindividual plant variation was presented for the first time by Herrera (2009). Here I will put forward a brief selection of ex- 

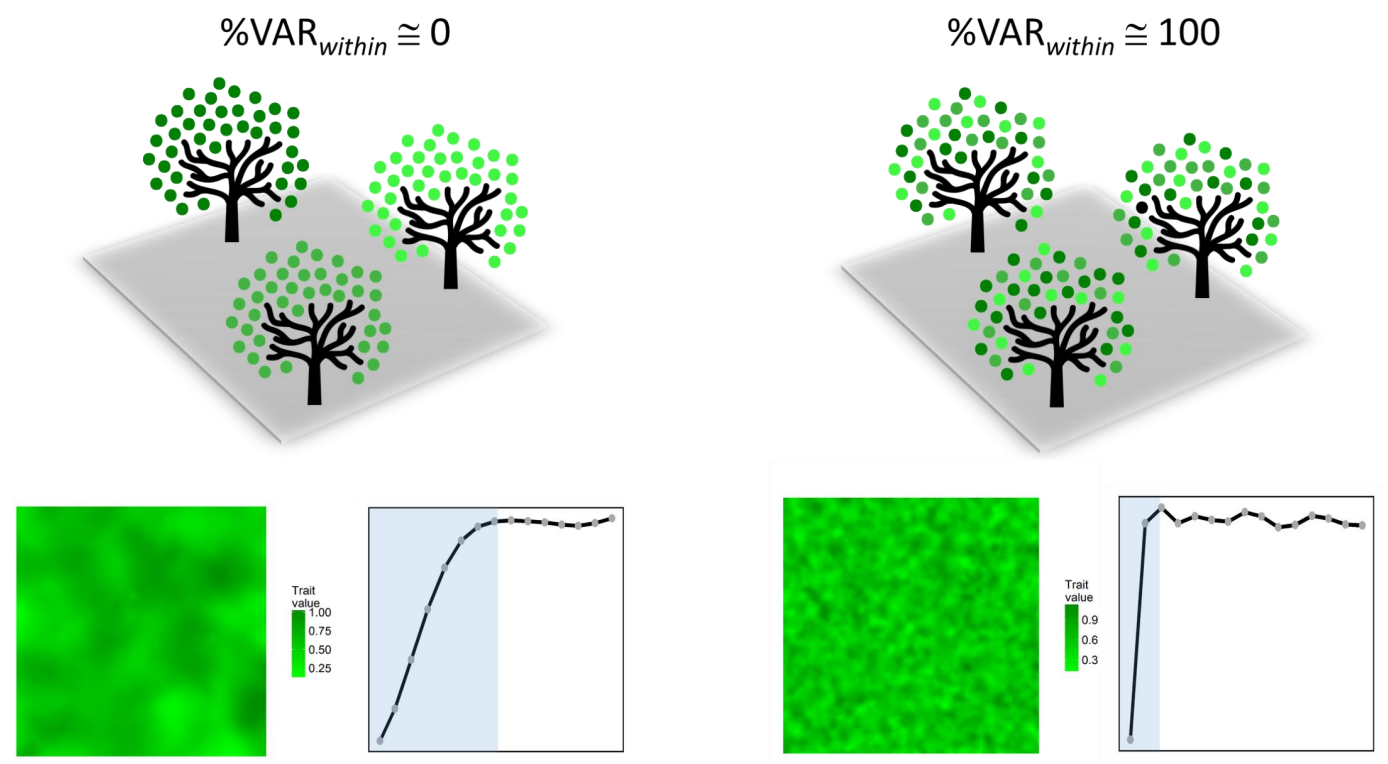

Figure 3. Schematic representation of two extreme situations in which most population-wide variance in a given quantitative trait of a reiterated organ occurs between (left, $\% \mathrm{VAR}_{\text {within }} \cong 0$ ) and within (right, $\% \mathrm{VAR}_{\text {within }} \cong 100$ ) individual plants. Trait values are denoted by variable color intensities. Hypothetical maps of spatially autocorrelated variation in trait values and its associated variogram plots are shown for the two situations. The variogram function for lag distance $h, \gamma(h)$, is the average squared difference of values separated by $h$. Blue areas denote the interval of distances between points within which trait values are spatially autocorrelated.

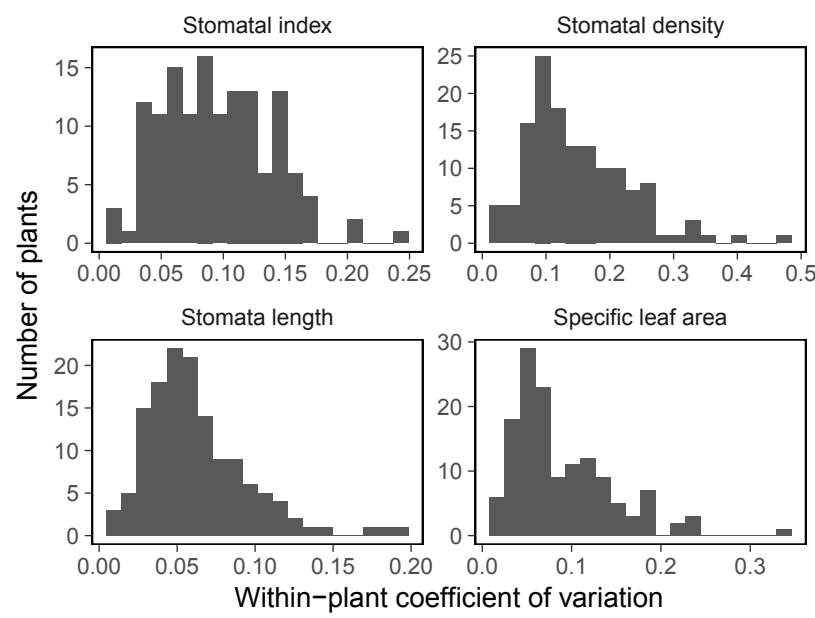

Figure 4. Frequency distributions of within-plant coefficients of variation (standard deviation/mean, a measurement of variability) for four functional leaf traits in a sample of $N=138$ individuals of the perennial herb Helleborus foetidus. Data from Herrera et al. (2015).

amples with the aim of illustrating the variety of mechanisms whereby within-plant heterogeneity in organ traits can impinge in complex ways on individual fecundity and performance, population dynamics, plant community functionality, and the behavior of animal consumers. Just for convenience of presentation, these effects will be split into two classes,

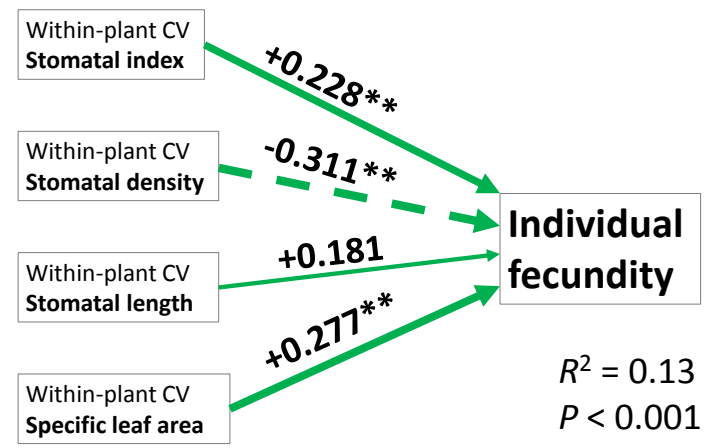

Figure 5. Simplified path diagram quantifying the effects of withinplant variability in four functional leaf traits on the fecundity (number of seeds produced) of Helleborus foetidus plants $(N=138)$. Arrow widths are proportional to the magnitude of path coefficients (shown beside arrows; ${ }^{* *} P<0.01$ ). Continuous and discontinuous lines reflect direct and inverse relationships, respectively. Based on data from Herrera et al. (2015) and M. Medrano and C. M. Herrera (unpublished).

namely those predominantly related to the plants themselves (e.g., effects on individual fecundity or population dynamics) and those impinging on the animals that exploit plant-based resources, such as, e.g., pollinators, seed predators, or herbivores. Drawing such a demarcation line between the two categories of effects, however, will often prove difficult in realworld scenarios, where effects on plants and animals will be in many instances closely intertwined (Herrera, 2009). 


\subsection{Effects on plant individuals, populations, and communities}

Within-plant variation in leaf, flower, fruit, or seed characteristics can affect diverse aspects of plant vegetative (e.g., growth rate, carbon assimilation) and reproductive (e.g., fecundity) performance of individuals, as shown by significant correlations across plants between subindividual variability and diverse measurements of individual performance (Herrera, 2009). In the case of leaves, it has been frequently suggested that subindividual variation in some of their functional traits may be advantageous to individuals by enhancing whole-plant photosynthetic performance and optimizing the exploitation of environmental variation (e.g., canopy light gradients; Givnish, 1988; Hollinger, 1996; Osada et al., 2014). For the perennial herb Helleborus foetidus, Herrera et al. (2015) suggested that variation in size, specific leaf area, and stomatal traits across leaves borne in different nodal positions along ramets could influence the water economy and carbon assimilation efficiency of whole plants, and suggested possible mechanisms in support of this explanation. Indirect support for their interpretation is provided by the significant relationships existing across individuals between seed fecundity and within-plant leaf variability (Fig. 5). The broad differences between individuals in subindividual variability of stomatal index, stomatal density, stomatal length, and specific leaf area illustrated in Fig. 4 collectively account for $13 \%$ of the variance in seed fecundity (Fig. 5). The higher the within-plant variability in stomatal index, stomatal length, and specific area, and the lower the variability in stomatal density, the higher was the total number of seeds produced by individual plants, perhaps as a consequence of improved water economy and/or carbon assimilation. Relationships between subindividual variability and fecundity can also hold across populations of the same species, as exemplified by the significant nonlinear relationship between mean individual fecundity and mean subindividual variability in specific leaf area across the populations of Helleborus foetidus sampled by Herrera et al. (2015) (Fig. 6).

Subindividual variability in flower, fruit, and seed traits may also influence the reproductive success of individuals, as illustrated by correlations across conspecific individuals between variability and some measurement of reproductive performance. For example, in plants of the southern Spanish violet Viola cazorlensis, subindividual variability in length of floral spur was related to fruit set (Herrera, 2009). In the tropical tree Ipomoea wolcottiana and the vine Passiflora incarnata, differences between plants in subindividual variability of anther-stigma separation were correlated with differences in fruit set and seed mass (Arceo-Gómez et al., 2017; Dai et al., 2017). In European populations of the bird-dispersed tree Crataegus monogyna, the magnitude of within-tree variation in fruit size was significantly related to the number of seeds effectively dispersed (Sobral et al., 2013). Further examples can be found in Herrera (2009).
Insofar as most organ traits involved in subindividual variation have some functional implications, variation within individuals will be consequential for the functional ecology of plant populations and communities. It is currently acknowledged that individual variation in functional traits broadens the ecological breadth of species (Sides et al., 2014) and is an important factor enhancing community-wide functional diversity (Siefert et al., 2015). In the same way that the incorporation of measurements of individual differences into traitbased plant ecology has improved our understanding of the role of trait variation in species distribution and plant community organization (Violle et al., 2012; Sides et al., 2014), I contend that the incorporation of subindividual variability into trait-based ecological studies will help to further sharpen the focus of, and lend biological realism to, functional ecology investigations. Subindividual variation will contribute to expanding the range of the biotic and abiotic resources which can be successfully exploited by single individuals (Herrera, 2009), and its neglect will tend to exaggerate the importance of individual differences as a source of total population- or community-wide functional diversity. To date, however, the subindividual component remains virtually unexplored from the perspective of its contribution to the functional diversity and trait-based organization of plant communities (Herrera et al., 2015). In the few studies where leaf trait variances between species, between individuals within species, and within individuals were quantified simultaneously for a plant community, the contribution of subindividual variation to total community-wide variance was sometimes comparable or even superior to that of individual variation (Auger and Shipley 2013; Kang et al., 2014).

\subsection{Effects on animal consumers}

In most terrestrial habitats, the aerial parts of modularly constructed plants provide the major structural scaffold for the establishment and trophic support of communities of heterotrophic organisms. From the perspective of animal consumers, therefore, an immediate consequence of subindividual plant variation in traits of homologous organs will be the appearance of a very small-scale component in the spatial distribution of some important resource parameters such as, e.g., concentration of water, nutrients and secondary compounds in leaves, amount and quality of the pollinator rewards available in flowers, nutritional quality of fleshy fruits, or size and defensive features of individual seeds (Herrera et al., 2006; Canto et al., 2007; Gijbels et al., 2014; Shimada et al., 2015). This low-level source of variation has two main implications for phytophagous animals of all sorts. First, since in most instances the size of animal consumers substantially exceeds the size of the individual plants with which they interact, animal consumers will have an opportunity to discriminate among not only individual plants, but also among the multiplicity of non-identical organs borne by each of them. And second, since individual plants differ not 

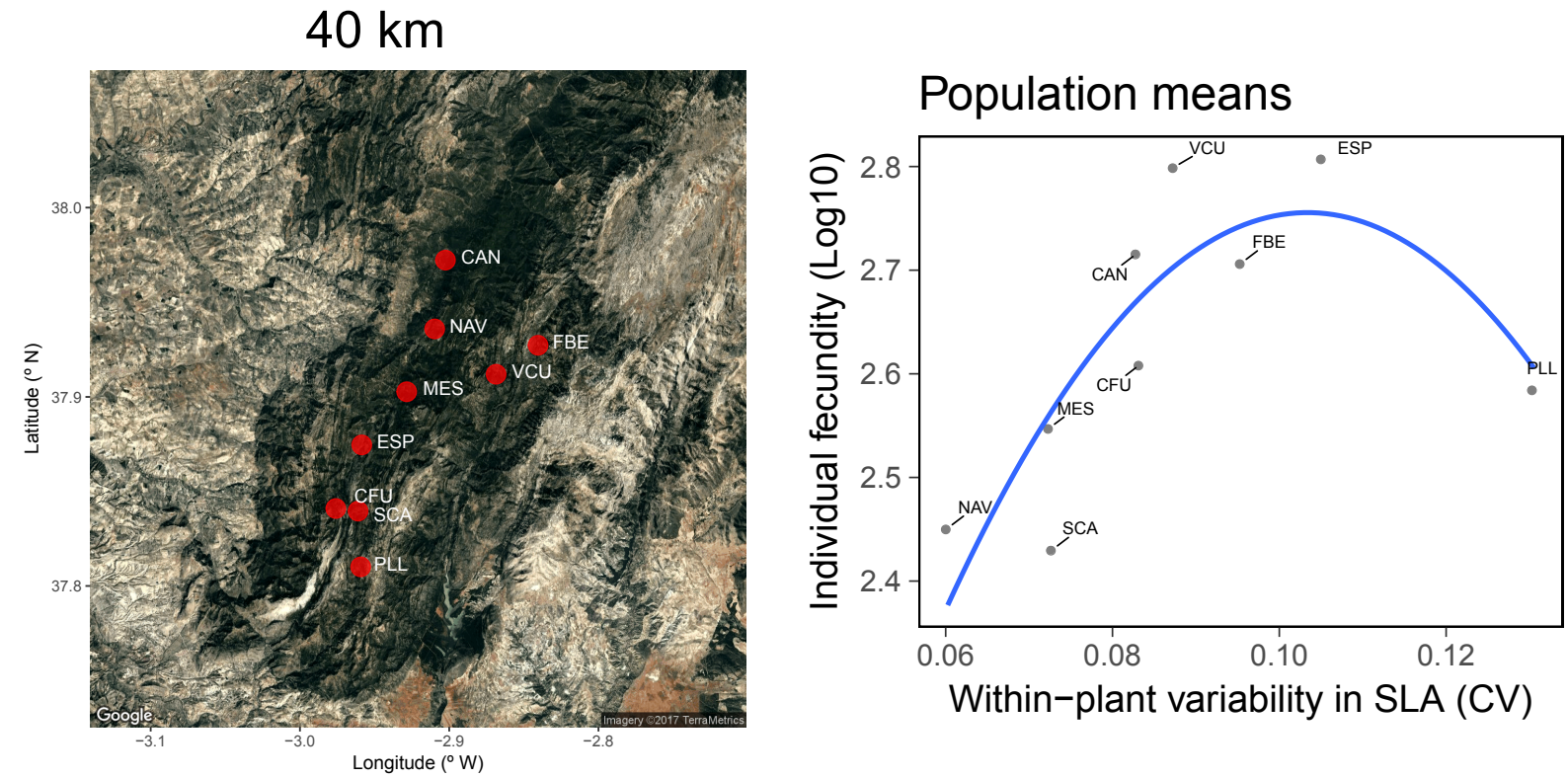

Figure 6. Geographical distribution of Helleborus foetidus populations sampled by Herrera et al. (2015) in the Sierra de Cazorla, southeastern Spain (left), and relationship across populations between mean individual fecundity (seeds produced per plant, log transformed) and mean within-individual variability (coefficient of variation, CV) of specific leaf area (SLA; right). Based on data from Herrera et al. (2015) and M. Medrano and C. M. Herrera (unpublished).

only in the mean value of organ traits, but also in the variance as noted earlier, consumer discrimination and choice among individual plants will also be influenced by individual differences in variability levels.

Within-plant variation in reiterated structures is generally comparable to or even greater in magnitude than variation among plants, as noted above. Therefore, discrimination and selection by animal consumers among organs that differ in morphological, chemical, or nutritional properties are likely to be the rule rather than the exception. This will apply equally to situations in which animals maintain predominantly antagonistic and predominantly mutualistic relationships with plants. It is well known, for instance, that after approaching a plant pollinators eventually visit only a subset of the flowers available, probing preferentially the most rewarding flowers and skipping the least rewarding ones (Duffield et al., 1993; Møller, 1995; Harder et al., 2004). Small-scale flower selection exerted by pollinators can be strong, with individual foragers rejecting up to $10-25 \%$ of approached flowers (Heinrich, 1979; Kadmon et al., 1991). Following arrival at a plant, frugivorous vertebrates also discern and respond to within-plant variation in fruit features related to energetic reward such as pulp mass or pulp-to-seed mass ratio (Wheelwright, 1985; Sallabanks, 1993; Palacio et al., 2017). Likewise, egg-laying females of invertebrate fruit and seed predators discriminate between the fruits borne by a plant on the basis of their size, number of enclosed seeds, or other traits potentially influencing the viability of their progeny (Herrera, 1984; Nalepa and Grissell, 1993). Similarly, leaf miners, sap feeders, or folivorous insects tend to select those particular leaves in a plant crown that provide greater nutritional reward and/or a lower load of toxic or deterrent compounds (Roslin et al., 2006; Young et al., 2010). In short, animal consumers generally do not treat individual plants as homogeneous feeding patches, but rather discriminate between organs borne on the same plant on the basis of differences in quality.

In addition to influencing the behavioral responses of animal consumers at the within-plant level, subindividual variation in organ traits will also impinge on foraging decisions that imply discrimination among plants. This important effect can be accounted for by the variance-sensitive behavior of animal consumers, for which within-patch variance in resource quality is equally or more important than within-patch mean value as a determinant of patch selection. Behavioral models have long predicted that such variancesensitive, or "risk-sensitive", behaviors should evolve when animals are regularly confronted with environmental patches that differ in the uncertainty (variance) of resource quality and fitness returns (Kacelnik and Bateson, 1996; Smallwood, 1996). One would therefore expect that, everything else being equal, relative preferences of animal consumers for individual plants should be inversely related to subindividual variability. Studies on floral visitors, frugivores, seed predators, and leaf eaters have provided substantial support for this prediction. For example, when insect and vertebrate nectarivores are offered a choice between feeding patches with contrasting variance in food reward (volume or concentration of 
sugar solutions), they most often develop variance-averse behaviors which lead them to prefer the least variable patches (Herrera, 2009; Nakamura and Kudo, 2016). In the fleshyfruited tree Crataegus monogyna, inverse relationships linking within-plant variability in fruit and seed mass, on the one hand, and proportional fruit removal by frugivorous birds and seed predation by rodents, on the other, have been reported (Sobral et al., 2013, 2014). Likewise, within-plant variances in the mass and tannin content of seeds in the oak Quercus serrata were significantly related to between-tree differences in seed removal by rodents (Shimada et al., 2015). Variable chemical defenses within plants will also have a negative impact on the performance of insect herbivores and favor the evolution of variance-driven host selection behaviors (Tenhumberg et al., 2000; Shelton, 2004; Wetzel et al., 2016).

\section{Evolutionary implications of subindividual variation: a canonical perspective}

The ecological processes associated with within-plant variation described above, particularly those related to the discriminating behavior of animals toward individual plants, can also have some evolutionary repercussions (Herrera, 2009). The two most important of these can be easily formulated using conventional tools from the realm of population genetics, and their consequences inferred from ordinary concepts of quantitative genetics and phenotypic selection models: subindividual variability will constrain responses to selection on individual organ traits, and phenotypic selection will operate not only on individual means, but also on withinindividual variances.

Simple quantitative genetics considerations reveal that within-plant variation in a given organ trait will generally act by constraining the responses to selection by the environment, including animals, on that trait. Repeatability $(r)$ of any organ trait in a plant population will approximately equal

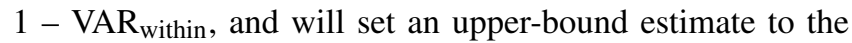
trait's broad-sense heritability $\left(H^{2}\right)$, or the fraction of the total phenotypic variance that has a genetic basis, both additive and nonadditive. Broad-sense heritability, in turn, sets an upper limit to narrow-sense heritability $\left(h^{2}\right)$, a central element in the familiar breeder's equation $\Delta \mu=h^{2} S$, where $\Delta \mu$ is the response to selection across generations and $S$ is the selection differential (see, e.g., Falconer and MacKay, 1996, and Lynch and Walsh, 1998, for further details). By setting an upper limit on $h^{2}$, repeatability of a trait will thus set an upper limit to the response to selection across generations. With the predominantly high values of $\mathrm{VAR}_{\text {within }}$ that characterize variation in the majority of organ traits (Fig. 1), repeatabilities for leaf, fruit, and seed traits will often be low enough to predict low heritabilities and thus intrinsically small responses to selection.
The most interesting and consequential evolutionary implication of within-plant variation in organ traits is that it opens the possibility for animals or the abiotic environment to exert selection on levels of within-plant variance through some of the mechanisms mentioned earlier. Selection on subindividual variability can be inferred from some results reviewed above (e.g., the relationship between leaf variability and individual fecundity in Helleborus foetidus plants shown in Fig. 5). More explicit tests, however, can be undertaken by expanding phenotypic selection models developed for evaluating selection on quantitative traits (Kingsolver and Pfennig, 2007) to incorporate subindividual variabilities just as another set of descriptors of a plant's phenotype in addition to customarily used means. Application of these "variability-aware", expanded phenotypic selection models to different plant species, organ traits, and types of plant-animal interactions has revealed the existence of significant directional selection on subindividual variability even in cases where selection on individual means was not evident (Herrera, 2009; Sobral et al., 2014; Arceo-Gómez et al., 2017; Palacio et al., 2017). Furthermore, function-valued trait analyses have revealed that the shape of gradients of variation in flower traits along inflorescences is also subject to phenotypic selection (Kulbaba et al., 2017).

Phenotypic selection on within-plant variability by biotic or abiotic agents acquires particular evolutionary relevance in the light of reports showing that within-plant trait variability has a genetic basis and, therefore, can respond adaptively to selection. Independent lines of experimental and correlative evidence point to a genetic basis for subindividual variability. Classical population genetics experiments have unequivocally shown that subindividual variabilities of parents and offspring are significantly correlated for a variety of leaf, flower, and seed traits (Paxman, 1956; Sakai and Shimamoto, 1965; Seyffert, 1983; Bagchi et al., 1989; Biere, 1991; Winn, 1996). On the other hand, two recent studies using genetic markers have found significant heritability for subindividual variability in flower developmental rates (Kulbaba et al., 2017) and significant associations across individuals between genetic markers and subindividual leaf trait variability (Herrera et al., 2015). To assess whether differences between Helleborus foetidus plants in leaf trait variability were related to their genetic features, Herrera et al. (2015) looked for statistically significant associations across plants between amplified fragment length polymorphism (AFLP) markers and the within-plant coefficients of variation for each of eight leaf traits. Significant relationships were found between the magnitude of subindividual variability in leaf traits and up to 11 different AFLP markers. Between 1 and 4 AFLP markers were associated with the within-plant variability level of each leaf trait. Although genetic marker-trait associations are unable to provide conclusive proofs of causality (Platt et al., 2010), these results are clearly compatible with the hypothesis that differences between $H$. foetidus plants in subindi- 
vidual variability in leaf features might have a causal genetic basis.

\section{Emerging connections: epigenetics and subindividual variation}

The evolutionary and ecological implications of within-plant variation in continuous traits of reiterated structures will ultimately depend on its underlying causes and maintenance mechanisms. A combination of position along growth axes, developmental history, short-term responses to the external environment, and developmental stochasticity has been proposed as a major proximate cause of subindividual variation, but its mechanistic basis is far from being well established (Herrera, 2009). Genetic mosaicism (i.e., withinplant heterogeneity in DNA sequences) caused by the vegetative propagation within individuals of somatic mutations was once proposed as a major driver of subindividual heterogeneity in plants (Whitham and Slobodchikoff, 1981). The rarity of documented instances of genetic mosaicism in wild plants, however, makes it unlikely that this will provide a universal mechanism for ubiquitous subindividual variation in plant communities (O'Connell and Ritland, 2004; Herrera, 2009; Padovan et al., 2013; Ranade et al., 2015). Nevertheless, genetic mosaicism is not the only possible mechanism causing stable or metastable subindividual genomic heterogeneity in plants. One further, hitherto almost unexplored source of genomic heterogeneity within plants is epigenetic mosaicism. A handful of studies have shown that the genomes of homologous organs in the same plant may differ in their patterns of DNA cytosine methylation despite homogeneity in the DNA sequence (Bitonti et al., 1996, 2002; Gao et al., 2010; Bian et al., 2013; Spens and Douhovnikoff, 2016; Ahn et al., 2017). Cytosine methylation is a major epigenetic mechanism in plants that plays important roles in gene expression and plant growth and development (Finnegan et al., 2000; Cokus et al., 2008; Lister et al., 2008), and it is well established that DNA methylation variants independent of DNA sequences are causally related to individual differences in continuous traits (Zhang et al., 2013; Cortijo et al., 2014; Hu et al., 2015; Kooke et al., 2015). Extrapolating from the betweenindividual to within-individual domains, the hypothesis has been recently formulated that subindividual heterogeneity in patterns and extent of DNA methylation can sometimes account for within-plant variation in organ traits (Herrera and Bazaga, 2013; Alonso et al., 2017). The few tests of this hypothesis conducted so far support a relationship between epigenetic mosaicism and subindividual heterogeneity in both discontinuously and continuously varying organ traits.

Individual holly trees (Ilex aquifolium) often bear a mixture of nonprickly and prickly leaves, the latter being produced facultatively as a plastic response to browsing by mammals (Obeso, 1997). By comparing genomic DNA methylation profiles in pairs of contiguous prickly and nonprickly leaves on the same branchlets using a methylation-sensitive amplified fragment polymorphism (MSAP) method, Herrera and Bazaga (2013) found that adjacent nonprickly and prickly leaves differed significantly in their genome-wide patterns of DNA methylation. Methylation differences between leaf types did not occur randomly across the genome, but affected predominantly some specific markers whose methylation probability declined significantly from nonprickly to contiguous prickly leaves. In this case, therefore, spatial correspondence within tree crowns between epigenotypes and leaf phenotypes was consistent with the hypothesis of epigenetic mosaicism as a contributing factor to subindividual variation.

Seeds are one of the most subindividually variable structures in plants, and in the vast majority of instances the within-plant component of population-wide variance in seed mass exceeds the variance between individuals (Fig. 1). The ecological significance of the large variation in seed mass occurring within crops was emphasized long ago by Janzen (1977a, b), and largely stems from the manifold implications of seed mass for population persistence and community dynamics through its pervasive effects on seed predation, seed dispersal, and seedling emergence and survival (Harper, 1977). The important ecological effects of seed mass variation thus confer particular interest to some recent results which link epigenetic mosaicism with subindividual variation in seed mass. In the evergreen shrub Lavandula latifolia, analyses of global DNA cytosine methylation levels using a HPLC method revealed that leaves from different modules in the same plant (one "module" = one inflorescence plus its associated set of subtending leaves) differed in global DNA cytosine methylation (Alonso et al., 2017). The magnitude of such epigenetic mosaicism was substantial, as variance in DNA methylation among modules of the same shrub was greater than variance between individuals. As predicted by the epigenetic mosaicism hypothesis, subindividual variation in the size and number of seeds produced per module was significantly related to subindividual variation in genome-wide DNA cytosine methylation level (Alonso et al., 2017).

Links between epigenetic mechanisms and subindividual variation in seed mass are probably far more complex than envisaged by the simple epigenetic mosaicism hypothesis, extending beyond the coordinated variation within individuals of methylation patterns and seed mass. This possibility was suggested by correlations across plants of the perennial herb Helleborus foetidus between DNA methylation transmissibility across generations and magnitude of subindividual variability in seed size (Herrera et al., 2014). In this species, individual plants differed in the fidelity with which DNA methylation patterns were transmitted from adult plants to descendant pollen. Such individual variation in methylation transmissibility, which was associated with genetic differences, was also related to within-plant variance in seed mass: individuals characterized by high plant-to-pollen trans- 
missibility of DNA methylation patterns was characterized by low subindividual variance in seed mass, and vice versa (Herrera et al., 2014).

\section{Synthesis and perspectives}

As noted by Herrera (2009, p. 339), "subindividual variation in plants seems to have succumbed so far to the risk of looking and yet overlooking." What is one of the most obvious sources of phenotypic variation in plant populations has been traditionally neglected, if not explicitly dismissed as a statistical nuisance, on the misguided understanding that such variation is the product of the same genotype and thus invisible to natural selection, or on the unproven implicit assumption that it is devoid of ecological relevance. Continuous subindividual variation is only rarely considered in ecology textbooks, and it is not even considered among the levels of biological diversity contributing to "biodiversity" (Contoli and Luiselli, 2015), an omission that will systematically underestimate the phenetic component of biodiversity in populations and communities. The preceding sections have summarized current knowledge on the magnitude, patterns, and ecological effects of subindividual variation in functional traits of all major classes of homologous, reiterated structures. Irrespective of the particular structure considered, whenever subindividual variation has been placed under the focus of ecological research and its correlates examined in sufficient detail, it has been found to be quantitatively important and ecologically significant at the population and community levels.

In addition to an immediate effect on the spatial structure of functional plant traits by enhancing environmental "fine-grainedness", the production by plants of nonidentical homologous structures has a number of more subtle ecological effects on both the plants themselves and their animal consumers. On the plant side, effects include broadening the ecological breadth of individuals and species; enhancing the functional diversity of populations and communities; improving the exploitation of limiting resources such as light or nutrients; modifying the outcome of interactions with antagonists (e.g., herbivores) and mutualists (e.g., pollinators); coping with environmental uncertainty in biotic and abiotic factors; and enhancing the exploitation of biotically and abiotically heterogeneous environments through "division of labor" effects (Herrera, 2009). Furthermore, differences between conspecific plants in subindividual variability are correlated with fitness surrogates and seem transgenerationally heritable, which lends plausibility to the hypothesis that variable levels of subindividual variability across populations may have been shaped by divergent natural selection (Herrera et al., 2014). On the side of animal consumers, the main predicted effect of subindividual variance in features of reiterated plant structures will be to elicit variance-sensitive foraging behaviors and to promote selectivity among plant individuals based on local trait variances rather than, or in addition to, local trait means. In the case of mutualists such as pollinators or seed dispersers, variance-averse behaviors will result in selection against the most subindividually variable individuals, whereas variance aversion by antagonists such as folivores or seed predators will select for increased subindividual variability (Herrera, 2009). In either case, in the long run the expected consequence for plants of such directional selection will be to shape natural patterns of subindividual variation in plant populations according to some organspecific trade-off representing a balance between the reduction promoted by plant-mutualist interactions and the enhancement arising from plant-antagonist interactions. Future studies aimed at understanding the ecological bases of population differentiation in plants should therefore consider not only population differences in trait means, but also population differences in subindividual trait variability and how these relate to spatially variable selection exerted by mutualistic and antagonistic animal consumers.

The experimental and observational studies conducted on wild populations of Helleborus foetidus and Lavandula latifolia reviewed above provide compelling evidence for a concerted action of both genetic and epigenetic factors in the control of subindividual variability in leaf and seed traits in these species. That epigenetic processes are apt to induce phenotypically heterogeneous seed crops by individual plants has long been known (McClintock, 1950; Banks and Fedoroff, 1989; Das and Messing, 1994), although this has only infrequently been acknowledged. Comparable evidence for subindividual variability in other reiterated organs such as flowers or fruits is still lacking, so the generality of intertwined genetic and epigenetic factors as jump-starters and drivers of that lowermost of all levels of phenotypic variation in plant communities cannot yet be ascertained. More generally, little is known about the ecological implications of epigenetic variation in natural populations. Unsurprisingly, looking for "the ecological causes and consequences of epigenetic variation" was recently singled out as one fundamental ecological question (Sutherland et al., 2013). Since then, studies on wild plants have documented relationships between epigenetic variation and functional diversity within and among individual plants (Alonso et al., 2014, 2017; Medrano et al., 2014; Herrera et al., 2015); relationships between epigenetic differences and ecological scenarios across conspecific populations that are largely unrelated to genetic differences (Schulz et al., 2014; Herrera et al., 2017); and the transgenerational transmission of patterns and extent of DNA methylation from maternal parents to offspring (Herrera et al., 2018). Additional observational and experimental studies are needed to establish the relationships between ecological and phenotypic measurements of plants and their epigenetic and genetic characteristics, in order to understand the possible three-way relationships linking subindividual variability, genetic features, and epigenetic mosaicism. One further line of inquiry should consider whether genomic methyla- 
tion patterns are inherited across generations and subindividual epigenetic mosaics do eventually translate into epigenetically heterogeneous progeny. Were these effects eventually proven, epigenetic mosaicism and its associated subindividual phenotypic variation would emerge as powerful, hitherto unrecognized factors contributing to the short- and long-term dynamics and functional diversity of plant populations and communities. And as a sequel, some ecology textbook would then choose "From organs to ecosystems" as a subtitle.

Data availability. See captions to Figs. 1, 2, 4, 5 and 6 for main data sources used in this paper.

Competing interests. The author declares that he has no conflict of interest.

Edited by: Daniel Montesinos

Reviewed by: two anonymous referees

\section{References}

Ahn, J., Franklin, S. B., and Douhovnikoff, V.: Epigenetic variation in clonal stands of aspen, Folia Geobot., 1-7, https://doi.org/10.1007/s12224-017-9308-x, online first, 2017.

Alonso, C.: Variaciones en las relaciones planta-insectos fitófagos: efectos de factores bióticos y abióticos, Unpubl. PhD Thesis, University of Sevilla, Sevilla, Spain, 1997.

Alonso, C., Pérez, R., Bazaga, P., Medrano, M., and Herrera, C. M.: Individual variation in size and fecundity is correlated with differences in global DNA cytosine methylation in the perennial herb Helleborus foetidus (Ranunculaceae), Am. J. Bot., 101, 1309-1313, 2014.

Alonso, C., Pérez, R., Bazaga, P., Medrano, M., and Herrera, C. M.: Within-plant variation in seed size and inflorescence fecundity is associated with epigenetic mosaicism in the shrub Lavandula latifolia (Lamiaceae), Ann. Bot., in press, https://doi.org/10.1093/aob/mcx140, 2017.

Arceo-Gómez, G., Vargas, C. F., and Parra-Tabla, V.: Selection on intra-individual variation in stigma-anther distance in the tropical tree Ipomoea wolcottiana (Convolvulaceae), Plant Biol., 19, 454-459, 2017.

Auger, S. and Shipley, B.: Inter-specific and intra-specific trait variation along short environmental gradients in an old-growth temperate forest, J. Veg. Sci., 24, 419-428, 2013.

Austen, E. J., Forrest, J. R. K., and Weis, A. E.: Within-plant variation in reproductive investment: consequences for selection on flowering time, J. Evol. Biol., 28, 65-79, 2015.

Bagchi, S. K., Sharma, V. P., and Gupta, P. K.: Developmental instability in leaves of Tectona grandis, Silvae Genet., 38, 1-6, 1989.

Banks, J. A. and Fedoroff, N.: Patterns of developmental and heritable change in methylation of the suppressor-mutator transposable element, Dev. Genet., 10, 425-437, 1989.

Barrett, S. C. H.: The evolution of mating strategies in flowering plants, Trends Plant Sci., 3, 335-341, 1998.
Begon, M., Townsend, C. R., and Harper, J. L.: Ecology, From individuals to ecosystems, 4th edn., Blackwell, Oxford, UK, 2006.

Bennett, J. O., Krishnan, A. H., Wiebold, W. J., and Krishnan, H. B.: Positional effect on protein and oil content and composition of soybeans, J. Agr. Food Chem., 51, 6882-6886, 2003.

Bian, R. J., Nie, D. D., Xing, F., Zhou, X. L., Gao, Y., Bai, Z. J., and Liu, B.: Adaptational significance of variations in DNA methylation in clonal plant Hierochloe glabra (Poaceae) in heterogeneous habitats, Aust. J. Bot., 61, 274-282, 2013.

Biere, A.: Parental effects in Lychnis flos-cuculi, I: seed size, germination and seedling performance in a controlled environment, J. Evol. Biol., 3, 447-465, 1991.

Bitonti, M. B., Cozza, R., Wang, G., Ruffini-Castiglione, M., Mazzuca, S., Castiglione, S., Sala, F., and Innocenti, A. M.: Nuclear and genomic changes in floating and submerged buds and leaves of heterophyllous waterchestnut (Trapa natans), Physiol. Plant., 97, 21-27, 1996.

Bitonti, M. B., Cozza, R., Chiappetta, A., Giannino, D., Castiglione, M. R., Dewitte, W., Mariotti, D., Van Onckelen, H., and Innocenti, A. M.: Distinct nuclear organization, DNA methylation pattern and cytokinin distribution mark juvenile, juvenile-like and adult vegetative apical meristems in peach (Prunus persica (L.) Batsch), J. Exp. Bot., 53, 1047-1054, 2002.

Canto, A., Pérez, R., Medrano, M., Castellanos, M. C., and Herrera, C. M.: Intraplant variation in nectar sugar composition in two Aquilegia species (Ranunculaceae): contrasting patterns under field and greenhouse conditions, Ann. Bot., 99, 653-660, 2007.

Casella, E. and Ceulemans, R.: Spatial distribution of leaf morphological and physiological characteristics in relation to local radiation regime within the canopies of 3-year-old Populus clones in coppice culture, Tree Physiol., 22, 1277-1288, 2002.

Cokus, S. J., Feng, S. H., Zhang, X. Y., Chen, Z. G., Merriman, B., Haudenschild, C. D., Pradhan, S., Nelson, S. F., Pellegrini, M., and Jacobsen, S. E.: Shotgun bisulphite sequencing of the Arabidopsis genome reveals DNA methylation patterning, Nature, 452, 215-219, 2008.

Contoli, L. and Luiselli, L.: Contributions to biodiversity theory: the importance of formal rigor, Web Ecol., 15, 33-37, https://doi.org/10.5194/we-15-33-2015, 2015.

Cortijo, S., Wardenaar, R., Colomé-Tatché, M., Gilly, A., Etcheverry, M., Labadie, K., Caillieux, E., Hospital, F., Aury, J. M., Wincker, P., Roudier, F., Jansen, R. C., Colot, V., and Johannes, F.: Mapping the epigenetic basis of complex traits, Science, 343, 1145-1148, 2014.

Dai, C., Liang, X. J., Ren, J., Liao, M. L., Li, J. Y., and Galloway, L. F.: The mean and variability of a floral trait have opposing effects on fitness traits, Ann. Bot., 117, 421-429, 2016.

Das, O. P. and Messing, J.: Variegated phenotype and developmental methylation changes of a maize allele originating from epimutation, Genetics, 136, 1121-1141, 1994.

Delhey, K. and Kempenaers, B.: Age differences in blue tit Parus caeruleus plumage colour: within-individual changes or colourbiased survival?, J. Avian Biol., 37, 339-348, 2006.

Duffield, G. E., Gibson, R. C., Gilhooly, P. M., Hesse, A. J., Inkley, C. R., Gilbert, F. S., and Barnard, C. J.: Choice of flowers by foraging honey bees (Apis mellifera): possible morphological cues, Ecol. Entomol., 18, 191-197, 1993. 
Ellsworth, D. S. and Reich, P. B.: Canopy structure and vertical patterns of photosynthesis and related leaf traits in a deciduous forest, Oecologia, 96, 169-178, 1993.

Escribano-Rocafort, A. G., Ventre-Lespiaucq, A. B., Granado-Yela, C., Rubio de Casas, R., Delgado, J. A., and Balaguer, L.: The expression of light-related leaf functional traits depends on the location of individual leaves within the crown of isolated Olea europaea trees, Ann. Bot., 117, 643-651, 2016.

Escribano-Rocafort, A. G., Ventre-Lespiaucq, A. B., Granado-Yela, C., Rubio de Casas, R., Delgado, J. A., Escudero, A., and Balaguer, L.: Intraindividual variation in light-related functional traits: magnitude and structure of leaf trait variability across global scales in Olea europaea trees, Trees, 31, 1505-1517, 2017.

Falconer, D. S. and MacKay, T. F. C.: Introduction to quantitative genetics, 4th edn., Addison Wesley Longman, Harlow, Essex, UK, 1996.

Finnegan, E. J., Peacock, W. J., and Dennis, E. S.: DNA methylation, a key regulator of plant development and other processes, Curr. Opin. Genet. Dev., 10, 217-223, 2000.

Gao, L. X., Geng, Y. P., Li, B., Chen, J. K., and Yang, J.: Genomewide DNA methylation alterations of Alternanthera philoxeroides in natural and manipulated habitats: implications for epigenetic regulation of rapid responses to environmental fluctuation and phenotypic variation, Plant Cell Environ., 33, 18201827, 2010.

Gijbels, P., Van den Ende, W., and Honnay, O.: Landscape scale variation in nectar amino acid and sugar composition in a Lepidoptera pollinated orchid species and its relation with fruit set, $\mathbf{J}$. Ecol., 102, 136-144, 2014.

Givnish, T. J.: Adaptation to sun and shade: a whole-plant perspective, Aust. J. Plant Physiol., 15, 63-92, 1988.

Guitián, J., Medrano, M., and Oti, J. E.: Variation in floral sex allocation in Polygonatum odoratum (Liliaceae), Ann. Bot., 94, 433440, 2004

Haldane, J. B. S.: Karl Pearson, 1857-1957, Biometrika, 44, 303313, 1957.

Haldane, J. B. S.: The theory of natural selection to-day, Nature, $183,710-713,1959$.

Harder, L. D., Jordan, C. Y., Gross, W. E., and Routley, M. B.: Beyond floricentrism: The pollination function of inflorescences, Plant Spec. Biol., 19, 137-148, 2004.

Harper, J. L.: Population biology of plants, Academic Press, London, UK, 1977.

Heinrich, B.: Resource heterogeneity and patterns of movement in foraging bumblebees, Oecologia, 40, 235-245, 1979.

Herrera, C. M.: Selective pressures on fruit seediness: differential predation of fly larvae on the fruits of Berberis hispanica, Oikos, 42, 166-170, 1984.

Herrera, C. M.: Multiplicity in unity. Plant subindividual variation and interactions with animals, University of Chicago Press, Chicago, USA, 2009.

Herrera, C. M. and Bazaga, P.: Epigenetic correlates of plant phenotypic plasticity: DNA methylation differs between prickly and nonprickly leaves in heterophyllous Ilex aquifolium (Aquifoliaceae) trees, Bot. J. Linn. Soc., 171, 441-452, 2013.

Herrera, C. M., Pérez, R., and Alonso, C.: Extreme intraplant variation in nectar sugar composition in an insect-pollinated perennial herb, Am. J. Bot., 93, 575-581, 2006.
Herrera, C. M., Medrano, M., and Bazaga, P.: Variation in DNA methylation transmissibility, genetic heterogeneity and fecundity-related traits in natural populations of the perennial herb Helleborus foetidus, Mol. Ecol., 23, 1085-1095, 2014.

Herrera, C. M., Medrano, M., and Bazaga, P.: Continuous withinplant variation as a source of intraspecific functional diversity: patterns, magnitude, and genetic correlates of leaf variability in Helleborus foetidus (Ranunculaceae), Am. J. Bot. 102, 225-232, 2015.

Herrera, C. M., Medrano, M., and Bazaga, P.: Epigenetic and genetic spatial structure of the perennial herb Helleborus foetidus: isolation by environment, isolation by distance, and functional trait divergence, Am. J. Bot., 104, 1195-1204, 2017.

Herrera, C. M., Alonso, C., Medrano, M., Pérez, R., and Bazaga, P.: Transgenerational epigenetics: inheritance of global cytosine methylation and methylation-related epigenetic markers in the shrub Lavandula latifolia, Am. J. Bot, submitted, 2018.

Hollinger, D. Y.: Optimality and nitrogen allocation in a tree canopy, Tree Physiol., 16, 627-634, 1996.

Hu, Y. D., Morota, G., Rosa, G. J. M., and Gianola, D.: Prediction of plant height in Arabidopsis thaliana using DNA methylation data, Genetics, 201, 779-793, 2015.

Imbert, E.: Ecological consequences and ontogeny of seed heteromorphism, Perspect. Plant Ecol., 5, 13-36, 2002.

Janzen, D. H.: Variation in seed size within a crop of a Costa Rican Mucuna andreana (Leguminosae), Am. J. Bot., 64, 347-349, 1977a.

Janzen, D. H.: Variation in seed weight in Costa Rican Cassia grandis (Leguminosae), Trop. Ecol., 18, 177-186, 1977b.

Kacelnik, A. and Bateson, M.: Risky theories - the effects of variance on foraging decisions, Am. Zool., 36, 402-434, 1996.

Kadmon, R., Shmida, A., and Selten, R.: Within-plant foraging behavior of bees and its relationship to nectar distribution in Anchusa strigosa, Israel J. Bot., 40, 283-94, 1991.

Kang, M., Chang, S. X., Yan, E. R., and Wang, X. H.: Trait variability differs between leaf and wood tissues across ecological scales in subtropical forests, J. Veg. Sci., 25, 703-714, 2014.

Kingsolver, J. G. and Pfennig, D. W.: Patterns and power of phenotypic selection in nature, Bioscience, 57, 561-572, 2007.

Kooke, R., Johannes, F., Wardenaar, R., Becker, F., Etcheverry, M., Colot, V., Vreugdenhil, D., and Keurentjes, J. J. B.: Epigenetic basis of morphological variation and phenotypic plasticity in Arabidopsis thaliana, Plant Cell, 27, 337-348, 2015.

Kulbaba, M. W., Clocher, I. C., and Harder, L. D.: Inflorescence characteristics as function-valued traits: analysis of heritability and selection on architectural effects, J. Syst. Evol., 55, 559-565, https://doi.org/10.1111/jse.12252, 2017.

Larrinaga, A. R. and Guitián, P.: Intraspecific variation in fruit size and shape in Corema album (Ericaceae) along a latitudinal gradient: from fruits to populations, Biol. J. Linn. Soc., 118, 940-950, 2016.

Le Roux, X., Sinoquet, H., and Vandame, M.: Spatial distribution of leaf dry weight per area and leaf nitrogen concentration in relation to local radiation regime within an isolated tree crown, Tree Physiol., 19, 181-188, 1999.

Lister, R., O’Malley, R. C., Tonti-Filippini, J., Gregory, B. D., Berry, C. C., Millar, A. H., and Ecker, J. R.: Highly integrated singlebase resolution maps of the epigenome in Arabidopsis, Cell, 133, 523-536, 2008. 
Lloyd, D. G.: Variation strategies of plants in heterogeneous environments, Biol. J. Linn. Soc., 21, 357-385, 1984.

Lynch, M. and Walsh, B.: Genetics and analysis of quantitative traits, Sinauer, Sunderland, Masachusetts, USA, 1998.

Marshall, C.: Sectoriality and physiological organisation in herbaceous plants: An overview, Vegetatio, 127, 9-16, 1996.

Matilla, A., Gallardo, M., and Puga-Hermida, M. I.: Structural, physiological and molecular aspects of heterogeneity in seeds: a review, Seed Sci. Res., 15, 63-76, 2005.

McClintock, B.: The origin and behavior of mutable loci in maize, P. Natl. Acad. Sci. USA, 36, 344-355, 1950.

Medrano, M., Herrera, C. M., and Bazaga, P.: Epigenetic variation predicts regional and local intraspecific functional diversity in a perennial herb, Mol. Ecol., 23, 4926-4938, 2014.

Møller, A. P.: Bumblebee preference for symmetrical flowers, P. Natl. Acad. Sci. USA, 92, 2288-2292, 1995.

Nakamura, S. and Kudo, G.: Foraging responses of bumble bees to rewardless floral patches: importance of withinplant variance in nectar presentation, AoB Plants, 8, plw037, https://doi.org/10.1093/aobpla/plw037, 2016.

Nalepa, C. A. and Grissell, E. E.: Host seed size and adult size, emergence, and morphology of Megastigmus aculeatus nigroflavus (Hymenoptera: Torymidae), Environ. Entomol., 22, 1313-1317, 1993.

Obeso, J. R.: The induction of spinescence in European holly leaves by browsing ungulates, Plant Ecol., 129, 149-156, 1997.

O'Connell, L. M. and Ritland, K.: Somatic mutations at microsatellite loci in western redcedar (Thuja plicata: Cupressaceae), J. Hered., 95, 172-176, 2004.

Orians, C. M. and Jones, C. G.: Plants as resource mosaics: a functional model for predicting patterns of within-plant resource heterogeneity to consumers based on vascular architecture and local environmental variability, Oikos, 94, 493-504, 2001.

Osada, N., Yasumura, Y., and Ishida, A.: Leaf nitrogen distribution in relation to crown architecture in the tall canopy species, Fagus crenata, Oecologia, 175, 1093-1106, 2014.

Padovan, A., Keszei, A., Foley, W. J., and Külheim, C.: Differences in gene expression within a striking phenotypic mosaic Eucalyptus tree that varies in susceptibility to herbivory, BMC Plant Biol., 13, 29-29, 2013.

Palacio, F. X., Girini, J. M., and Ordano, M.: Linking the hierarchical decision-making process of fruit choice and the phenotypic selection strength on fruit traits by birds, J. Plant Ecol., 10, 713720, 2017.

Paxman, G. J.: Differentiation and stability in the development of Nicotiana rustica, Ann. Bot.-London, 20, 331-347, 1956.

Pérez-Harguindeguy, N., Díaz, S., Garnier, E., Lavorel, S., Poorter, H., Jaureguiberry, P., Bret-Harte, M. S., Cornwell, W. K., Craine, J. M., Gurvich, D. E., Urcelay, C., Veneklaas, E. J., Reich, P. B., Poorter, L., Wright, I. J., Ray, P., Enrico, L., Pausas, J. G., de Vos, A. C., Buchmann, N., Funes, G., Quétier, F., Hodgson, J. G., Thompson, K., Morgan, H. D., ter Steege, H., van der Heijden, M. G. A., Sack, L., Blonder, B., Poschlod, P., Vaieretti, M. V., Conti, G., Staver, A. C., Aquino, S., and Cornelissen, J. H. C.: New handbook for standardised measurement of plant functional traits worldwide, Aust. J. Bot., 61, 167-234, 2013.

Perica, S.: Seasonal fluctuation and intracanopy variation in leaf nitrogen level in olive, J. Plant Nutr., 24, 779-787, 2001.
Piersma, T. and Lindström, ̊..: Rapid reversible changes in organ size as a component of adaptive behaviour, Trends Ecol. Evol., 12, 134-138, 1997.

Platt, A., Vilhjálmsson, B. J., and Nordborg, M.: Conditions under which genome-wide association studies will be positively misleading, Genetics, 186, 1045-1052, 2010.

Price, E. A. C., Hutchings, M. J., and Marshall, C.: Causes and consequences of sectoriality in the clonal herb Glechoma hederacea, Vegetatio, 127, 41-54, 1996.

Ranade, S. S., Ganea, L. S., Razzak, A. M., and Gil, M. R. G.: Fungal infection increases the rate of somatic mutation in Scots Pine (Pinus sylvestris L.), J. Hered., 106, 386-394, 2015.

Roslin, T., Gripenberg, S., Salminen, J. P., Karonen, M., O'Hara, R. B., Pihlaja, K., and Pulkkinen, P.: Seeing the trees for the leaves - oaks as mosaics for a host-specific moth, Oikos, 113, 106-120, 2006.

Roy, S. K.: Regulation of morphogenesis in an oleaceous tree, $\mathrm{Nyc}$ tanthes arbor-tristis, Nature, 183, 1410-1411, 1959.

Sakai, K. I. and Shimamoto, Y.: Developmental instability in leaves and flowers of Nicotiana tabacum, Genetics, 51, 801-813, 1965.

Sallabanks, R.: Hierarchical mechanisms of fruit selection by an avian frugivore, Ecology, 74, 1326-1336, 1993.

Schulz, B., Eckstein, R. L., and Durka, W.: Epigenetic variation reflects dynamic habitat conditions in a rare floodplain herb, Mol. Ecol., 23, 3523-3537, 2014.

Seyffert, W.: Homeostasis in defined genotypes of Matthiola incana, Theor. Appl. Genet., 64, 205-212, 1983.

Shelton, A. L.: Variation in chemical defences of plants may improve the effectiveness of defence, Evol. Ecol. Res., 6, 709-726, 2004.

Shimada, T., Takahashi, A., Shibata, M., and Yagihashi, T.: Effects of within-plant variability in seed weight and tannin content on foraging behaviour of seed consumers, Funct. Ecol., 29, 15131521, 2015.

Sides, C. B., Enquist, B. J., Ebersole, J. J., Smith, M. N., Henderson, A. N., and Sloat, L. L.: Revisiting Darwin's hypothesis: Does greater intraspecific variability increase species' ecological breadth?, Am. J. Bot., 101, 56-62, 2014.

Siefert, A., Violle, C., Chalmandrier, L., Albert, C. H., Taudiere, A., Fajardo, A., Aarssen, L. W., Baraloto, C., Carlucci, M. B., Cianciaruso, M. V., Dantas, V. D., de Bello, F., Duarte, L. D. S., Fonseca, C. R., Freschet, G. T., Gaucherand, S., Gross, N., Hikosaka, K., Jackson, B., Jung, V., Kamiyama, C., Katabuchi, M., Kembel, S. W., Kichenin, E., Kraft, N. J. B., Lagerstrom, A., Le Bagousse-Pinguet, Y., Li, Y. Z., Mason, N., Messier, J., Nakashizuka, T., Overton, J. McC., Peltzer, D. A., Perez-Ramos, I. M., Pillar, V. D., Prentice, H. C., Richardson, S., Sasaki, T., Schamp, B. S., Schöb, C., Shipley, B., Sundqvist, M., Sykes, M. T., Vandewalle, M., and Wardle, D. A.: A global meta-analysis of the relative extent of intraspecific trait variation in plant communities, Ecol. Lett., 18, 1406-1419, 2015.

Smallwood, P. D.: An introduction to risk sensitivity: the use of Jensen's inequality to clarify evolutionary arguments of adaptation and constraint, Am. Zool., 36, 392-401, 1996.

Sobral, M., Guitián, J., Guitián, P., and Larrinaga, A. R.: Selective pressure along a latitudinal gradient affects subindividual variation in plants, PLoS One, 8, e74356, https://doi.org/10.1371/journal.pone.0074356, 2013. 
Sobral, M., Guitián, J., Guitián, P., and Larrinaga, A. R.: Seed predators exert selection on the subindividual variation of seed size, Plant Biol., 16, 836-842, 2014.

Spens, A. E. and Douhovnikoff, V.: Epigenetic variation within Phragmites australis among lineages, genotypes, and ramets, Biol. Invasions, 18, 2457-2462, 2016.

Stamps, J. A., Briffa, M., and Biro, P. A.: Unpredictable animals: individual differences in intraindividual variability (IIV), Anim. Behav., 83, 1325-1334, 2012.

Suomela, J. and Ayres, M. P.: Within-tree and among-tree variation in leaf characteristics of mountain birch and its implications for herbivory, Oikos, 70, 212-222, 1994.

Sutherland, W. J., Freckleton, R. P., Godfray, H. C. J., Beissinger, S. R., Benton, T., Cameron, D. D., Carmel, Y., Coomes, D. A., Coulson, T., Emmerson, M. C., Hails, R. S., Hays, G. C., Hodgson, D. J., Hutchings, M. J., Johnson, D., Jones, J. P. G., Keeling, M. J., Kokko, H., Kunin, W. E., Lambin, X., Lewis, O. T., Malhi, Y., Mieszkowska, N., Milner-Gulland, E. J., Norris, K., Phillimore, A. B., Purves, D. W., Reid, J. M., Reuman, D. C., Thompson, K., Travis, J. M. J., Turnbull, L. A., Wardle, D. A., and Wiegand, T.: Identification of 100 fundamental ecological questions, J. Ecol., 101, 58-67, 2013.

Tenhumberg, B., Tyre, A. J., and Roitberg, B.: Stochastic variation in food availability influences weight and age at maturity, J. Theor. Biol., 202, 257-272, 2000.

Violle, C., Enquist, B. J., McGill, B. J., Jiang, L., Albert, C. H., Hulshof, C., Jung, V., and Messier, J.: The return of the variance: intraspecific variability in community ecology, Trends Ecol. Evol., 27, 244-252, 2012.

Watson, M. A.: Integrated physiological units in plants, Trends Ecol. Evol., 1, 119-123, 1986.
Wells, C. L. and Pigliucci, M.: Adaptive phenotypic plasticity: the case of heterophylly in aquatic plants, Perspect. Plant Ecol., 3, $1-18,2000$.

Wetzel, W. C., Kharouba, H. M., Robinson, M., Holyoak, M., and Karban, R.: Variability in plant nutrients reduces insect herbivore performance, Nature, 539, 425-427, 2016.

Wheelwright, N. T.: Fruit size, gape width, and the diets of fruiteating birds, Ecology, 66, 808-818, 1985.

White, J.: The plant as a metapopulation, Annu. Rev. Ecol. Syst., 10, 109-145, 1979.

Whitham, T. G. and Slobodchikoff, C. N.: Evolution by individuals, plant-herbivore interactions, and mosaics of genetic variability: the adaptive significance of somatic mutations in plants, Oecologia, 49, 287-292, 1981.

Winn, A. A.: Adaptation to fine-grained environmental variation: an analysis of within-individual leaf variation in an annual plant, Evolution, 50, 1111-1118, 1996.

Young, B., Wagner, D., Doak, P., and Clausen, T.: Within-plant distribution of phenolic glycosides and extrafloral nectaries in trembling aspen (Populus tremuloides; Salicaceae), Am. J. Bot., 97, 601-610, 2010.

Zhang, Y. Y., Fischer, M., Colot, V., and Bossdorf, O.: Epigenetic variation creates potential for evolution of plant phenotypic plasticity, New Phytol., 197, 314-322, 2013.

Zywiec, M., Delibes, M., and Fedriani, J. M.: Microgeographical, inter-individual, and intra-individual variation in the flower characters of Iberian pear Pyrus bourgaeana (Rosaceae), Oecologia, 169, 713-722, 2012. 